\title{
EWS-erg and EWS-Fli1 Fusion Transcripts in Ewing's Sarcoma and Primitive Neuroectodermal Tumors with Variant Translocations
}

\author{
Marco Giovannini, * Jaclyn A. Biegel, ${ }^{*}$ Massimo Serra, $\$$ Jian-Ying Wang, * Yalin H. Wei, * Lynn Nycum, ${ }^{*}$ \\ Beverly S. Emanuel, ${ }^{\ddagger}$ and Glen A. Evans* \\ *Molecular Genetics Laboratory, The Salk Institute for Biological Studies, La Jolla, California 92037; ${ }^{\ddagger}$ Division of Human Genetics and \\ Molecular Biology, Children's Hospital, and Department of Pediatrics, University of Pennsylvania School of Medicine, Philadelphia, \\ Pennsylvania 19104; and ${ }^{\S}$ Laboratory of Oncological Research, Istituti Ortopedici Rizzoli, Bologna, 40136 Italy
}

\begin{abstract}
We have determined the frequency of EWS fusion transcripts in a series of primary Ewing's sarcomas and peripheral primitive neuroectodermal tumors and cell lines. Type 1 and 2 EWS-Fli1 fusions were demonstrated in 8 cell lines and 14 patient samples. Five patients with cytogenetically characterized rearrangements of chromosome 22 that did not involve chromosome 11 were included in these studies. A novel EWS-Fli1 in-frame isoform fusing EWS to exon 8 of Fli1 was isolated from a tumor with a variant $t(12 ; 22 ; 22)(q 14 ; p 1 ; q 12)$ translocation. Three in-frame isoforms of a novel hybrid transcript derived from the fusion of EWS with the ETS domain of the human erg gene were identified in patient samples and a cell line with cytogenetically unidentified or cryptic translocations involving chromosomes 21 and 22 . Interphase analysis by fluorescent in situ suppression hybridization using two overlapping erg yeast artificial chromosome clones demonstrated disruption of the erg gene on chromosome 21 in a patient sample with monosomy 22 . Our results provide new information about the involvement of EWS in small round cell tumors involving exchange of its putative RNA-binding domain with DNA-binding domains derived from different members of the ETS family of transcription factors. These studies emphasize the utility of reverse transcriptase PCR analysis and fluorescent in situ hybridization as additional diagnostic tools for differential diagnosis among small round cell tumors. (J. Clin. Invest. 1994. 94:489-496.) Key words: small round cell tumors $\bullet$ chromosomal translocations $\bullet$ yeast artificial chromosomes - fluorescent in situ hybridization • interphase cytogenetics
\end{abstract}

\section{Introduction}

Ewing's sarcoma (ES) ${ }^{1}$ is a highly malignant tumor of bone and soft tissues that most often affects young adolescents (1).

Address correspondence to Dr. Marco Giovannini, (present address) Laboratoire de Génétique des Tumeurs, Institut Curie, 26 Rue d'Ulm, 75231 Paris Cedex 05, France.

Received for publication 22 November 1993 and in revised form 2 March 1994.

1. Abbreviations used in this paper: AT, Askin's tumor; ES, Ewing's sarcoma; FISSH, fluorescent in situ suppression hybridization; PN, peripheral neuroepithelioma; PNET, primitive neuroectodermal tumors; RT-PCR, reverse transcription PCR; SRCT, small round cell tumors; YAC, yeast artificial chromosomes.

J. Clin. Invest.

(c) The American Society for Clinical Investigation, Inc. 0021-9738/94/08/0489/08 \$2.00

Volume 94, August 1994, 489-496
Approximately $83 \%$ of all cases are associated with a $t(11 ; 22)(q 24 ; q 12)$ reciprocal translocation (2-4). Cytogenetically identical translocations have been described in other small round cell tumors (SRCT) such as primitive neuroectodermal tumor (PNET), peripheral neuroepithelioma (PN), and Askin's tumor (AT) (5). The recent cloning of the EWS and Fli1 genes disrupted by the $t(11 ; 22)(\mathrm{q} 24 ; \mathrm{q} 12)$ reciprocal translocation characteristic of these SRCT has provided new insight into possible mechanisms of tumorigenesis in solid tumors (6). Further, the cloning of hybrid fusion transcripts between EWS and the ATF-1 transcription factor gene in malignant melanoma of soft parts with a balanced $\mathrm{t}(12 ; 22)(\mathrm{q} 13 ; \mathrm{q} 12)$ translocation (7), the fusion of TLS (translocated in liposarcoma) gene with CHOP gene (member of the c/EBP family of transcriptional activators ) as a result of the $t(12 ; 16)(q 13 ; p 11)$ translocation in myxoid liposarcoma (8), and the fusion of PAX3 gene to a member of the forkhead gene family in alveolar rhabdomyosarcomas with a $\mathrm{t}(2 ; 13)(\mathrm{q} 35 ; \mathrm{q} 14)$ translocation $(9,10)$ suggest a common mechanism of activation of transcription factors that is responsible for development of different tumor types.

Human Fli1 (11) is a member of the ETS family of transcription factors that exhibit homology within a conserved DNA-binding domain, termed the 3 '-ETS domain (12). EWS (6) is a gene of unknown function with extensive sequence similarity to TLS (8). Both belong to a new subclass of RNAbinding proteins that contain a conserved 80-amino acid domain in their carboxyl terminus (13). The ES- and PNETassociated $\mathrm{t}(11 ; 22)(\mathrm{q} 24 ; \mathrm{q} 12)$ translocation results in a hybrid mRNA transcribed from the derivative chromosome 22 , in which the 3 ' DNA-binding domain of Fli1 replaces the 3 ' RNAbinding domain of EWS (6). Hybrid EWS-Flil constructs induce malignant transformation when introduced into murine fibroblasts (14). EWS-Fli1 fusion genes are heterogeneous since three different breakpoints in Fli1 and two breakpoints in EWS have been described so far, resulting in four unique fusion sequences $(6,14)$. The incidence of the different fusion transcripts in a large number of patients has not yet been determined. Variant and complex translocations have been reported in $9 \%$ of all ES and PNET cases $(4,15)$. In most instances they involve chromosome $22 \mathrm{q} 12$, suggesting that the fusion gene on the derivative chromosome 22 is related to tumorigenesis. Molecular studies published to date demonstrated that all ES and PNET with typical $\mathrm{t}(11 ; 22)(\mathrm{q} 24 ; \mathrm{q} 12)$ translocations and one ES cell line with a complex $t(11 ; 22 ; 14)$ translocation contained EWS-Fli1 fusion transcripts $(6,14,16)$. Rearrangements of the EWS and Fli1 genes were also found in two tumors with variant $t(7 ; 22)$ and $t(14 ; 22)$ translocations and in one tumor with a normal karyotype (17). These findings are similar to the cases of chronic myeloid leukemia in which cytogenetic analysis does not demonstrate the typical $\mathrm{t}(9 ; 22)(\mathrm{q} 34 ; \mathrm{q} 11)$ translocation yet contains bcr-abl chimeric transcripts (18). 
Table I. Pathological and Cytogenetic Characteristics of the Cell Lines and Tumors

\begin{tabular}{|c|c|c|c|c|}
\hline & Age/sex & Diagnosis & Partial karyotype & Fusion \\
\hline \multicolumn{5}{|l|}{ Cell line (reference) } \\
\hline TC-71 (5) & $22 / \mathrm{M}$ & ES of bone & $\mathrm{t}(11 ; 22)(\mathrm{q} 24 ; \mathrm{q} 12)$ & Type 1 \\
\hline $6647(5)$ & $14 / F$ & ES of bone & $\mathrm{t}(11 ; 22)(\mathrm{q} 24 ; \mathrm{q} 12), 22 \mathrm{q}+$ & Type 2 \\
\hline SK-ES-1 & $18 / \mathrm{M}$ & ES of bone & $\mathrm{t}(11 ; 22)(\mathrm{q} 24 ; \mathrm{q} 12)$ & Type 2 \\
\hline RD-ES & 19/M & ES of bone & $22 q-$ & Type 2 \\
\hline TC-32 (5) & $17 / \mathrm{F}$ & PN & $t(11 ; 22)(q 24 ; q 12)$ & Type 2 \\
\hline LAP-35 (23) & $12 / \mathrm{F}$ & PNET of bone & $\mathrm{t}(11 ; 22)(\mathrm{q} 24 ; \mathrm{q} 12)$ & Type 2 \\
\hline SK-PN-LI (24) & $3 / \mathbf{M}$ & PNET of bone & $\mathrm{t}(21 ; 22)(\mathrm{q} 22 ; \mathrm{q} 12)$ & Type 9e \\
\hline SK-PN-DW (24) & $17 / \mathrm{M}$ & PNET of soft parts & $-11 ; \mathrm{t}(11 ; 22)(\mathrm{q} 24 ; \mathrm{q} 12)$ & Type 1 \\
\hline SK-N-MC (5) & $14 / \mathrm{F}$ & AT of chest wall & $\mathrm{t}(2 ; 11 ; 22 ; 21)(\mathrm{q} 32 ; \mathrm{q} 24 ; \mathrm{q} 12 ; \mathrm{p} 11)$ & Type 1 \\
\hline U20S (25) & $15 / \mathrm{F}$ & Osteosarcoma & Complex abnormalities & None \\
\hline SK-N-SH & $4 / F$ & Neuroblastoma & $\operatorname{der}(22) t(22 ; ?)(q 13 ; ?)$ & None \\
\hline \multicolumn{5}{|l|}{ Tumor } \\
\hline T89-135 & $17 / \mathrm{M}$ & SRCT consistent with ES & -22 & Type le \\
\hline T91-124 & $11 / \mathrm{M}$ & PNET & $\begin{array}{l}\operatorname{der}(21) t(21 ; ?)(q 22 ; ?) \\
? \operatorname{der}(22) t(22 ; ?)(\mathrm{q} 12 ; 2)\end{array}$ & Type 1e \\
\hline T92-60 & $11 / \mathrm{F}$ & ES of bone & $\operatorname{der}(22) t(22 ; ?)(q 12 ; ?)$ & Type $3 \mathrm{e}$ \\
\hline T93-98 & $12 / \mathrm{F}$ & $\begin{array}{l}\text { SRCT consistent with } \\
\text { alveolar rhabdomyosarcoma }\end{array}$ & $\begin{array}{l}-22 \\
\operatorname{der}(16) t(16 ; 22)(q ? 23 ; q 11-12) \\
\operatorname{der}(22) t(22 ; ?)(q 11-12 ; ?)\end{array}$ & None \\
\hline T93-101 & $14 / F$ & ES & $\mathrm{t}(11 ; 22)(\mathrm{q} 24 ; \mathrm{q} 12)$ & Type 2 \\
\hline T93-113 & $13 / \mathrm{M}$ & SRCT consistent with PNET & $\mathrm{t}(12 ; 22 ; 22)(\mathrm{q} 14 ; \mathrm{p} 1 ; \mathrm{q} 12)$ & Type 8 \\
\hline
\end{tabular}

Variants of specific chromosomal translocations in multiple leukemia subtypes have been reported. The cloning of some of these rare variant translocations has led to the discovery of new genes that share sequence homology and/or common motifs with the gene disrupted by the "typical" translocation. A notable example is the group of translocations that fuse the MLL gene on 11q23 (19-21) to genes from a variety of different chromosomes (22). These genes share extensive sequence homology and presumably confer similar biological activities to the chimeric protein. Cloning of the genes involved in variant translocations in solid tumors should also result in an increased understanding of the mechanisms involved in the development of these malignancies.

In this study, we have investigated the frequency and specificity of EWS alterations in a series of cell lines and tumors obtained from patients with SRCT. Cell lines and tumor specimens with typical $t(11 ; 22)$ translocations and with rearrangements of chromosome 22 in the presence of normal chromosomes 11 were characterized cytogenetically and studied with molecular techniques. Novel transcripts involving EWS and the ETS family-related erg or Fli1 genes were observed, expanding the repertoire of possible gene rearrangements involved in the pathogenesis of ES and PNET.

\section{Methods}

Cell lines and patient samples. 11 tumor cell lines were analyzed in this study. Their clinical features at diagnosis and partial karyotypes are listed in Table I (23-25). Cell lines RD-ES, SK-ES, SK-N-MC, SK-N$\mathrm{SH}$, and U2OS were obtained from the American Type Culture Collection (Rockville, MD). Six SRCT cases were cytogenetically characterized at The Children's Hospital of Philadelphia, according to standard methods (26). Cytogenetic abnormalities of the relevant chromosomes are listed in Table I. 17 patient samples of cytologically, histologically, and immunohistochemically confirmed SRCTs were not characterized cytogenetically and were obtained from the Istituti Ortopedici Rizzoli, Bologna, Italy. Surgical tumor samples were cryopreserved before their use in these studies. Informed consent was obtained according to institutional guidelines.

Reverse transcription PCR (RT-PCR) analysis of EWS-Flil and $E W S$-erg fusions. Total RNA was isolated from frozen tumor fragments and from cell lines in culture as described (27). $1 \mu \mathrm{g}$ of total RNA was reverse transcribed with an oligo-d $(\mathrm{T})_{16}$ primer using the GeneAmp RNA-PCR kit (Perkin-Elmer Corp., Norwalk, CT). PCR amplification was performed with $2.5 \mathrm{U}$ of Taq DNA polymerase, $2 \mathrm{mM} \mathrm{MgCl}$, $1 \times$ PCR buffer II (Perkin-Elmer Corp.), $200 \mu \mathrm{M}$ deoxynucleotide triphosphate, and $0.15 \mu \mathrm{M}$ each 5' and 3' primers. Oligonucleotide 22.1 (7) or 22.3 (6) were used as 5' (forward) EWS primers. Primer 11.3 (6) was the reverse primer on exon 9 of the human Flil gene (Zucman, J., T. Melot, B. Plougastel, L. Selleri, M. Giovannini, G. A. Evans, O. Delattre, and G. Thomas, manuscript submitted for publication). The reverse primer for the human erg gene (28) 21.9, 5'-ATGAGAAGGCATATGGCTGG-3', was used to specifically amplify erg moieties. The amplification profile consisted of denaturation at $94^{\circ} \mathrm{C}$ for $30 \mathrm{~s}$, primer annealing at $65^{\circ} \mathrm{C}$ for $60 \mathrm{~s}$, and extension at $72^{\circ} \mathrm{C}$ for $2 \mathrm{~min}$, for a total of 30 cycles on an automated heat block (GeneAmp PCR system 9600; Perkin Elmer-Cetus Instruments, Norwalk, CT). Positive and negative controls were carried through all steps. As a positive control for the integrity of RNA isolated from each tumor and cell line, PCR amplification of the $\beta$-actin gene was performed using forward primer $\beta A 1$ (nucleotides 2563-2582 of GenBank M10277) in combination with reverse primer $\beta$ A2 (nucleotides 2970-2989 of GenBank M10277), which produce a 314-bp product.

Direct sequencing of PCR products. PCR products were purified and concentrated on a Microcon 100 (Amicon, Beverly, MA). Primer 22.3 (6) was used for sequencing of EWS-Fli1 and EWS-erg PCR products using a Taq DyeDeoxy terminator cycle sequencing kit (Applied Biosystems, Inc., Foster City, CA). Reactions were run and analyzed on a fluorescent DNA sequencer (373A; Applied Biosystems, Inc.).

Multicolor fluorescent in situ hybridization with erg yeast artificial chromosomes (YACs). Metaphase spreads and interphase nuclei were 


\section{A}
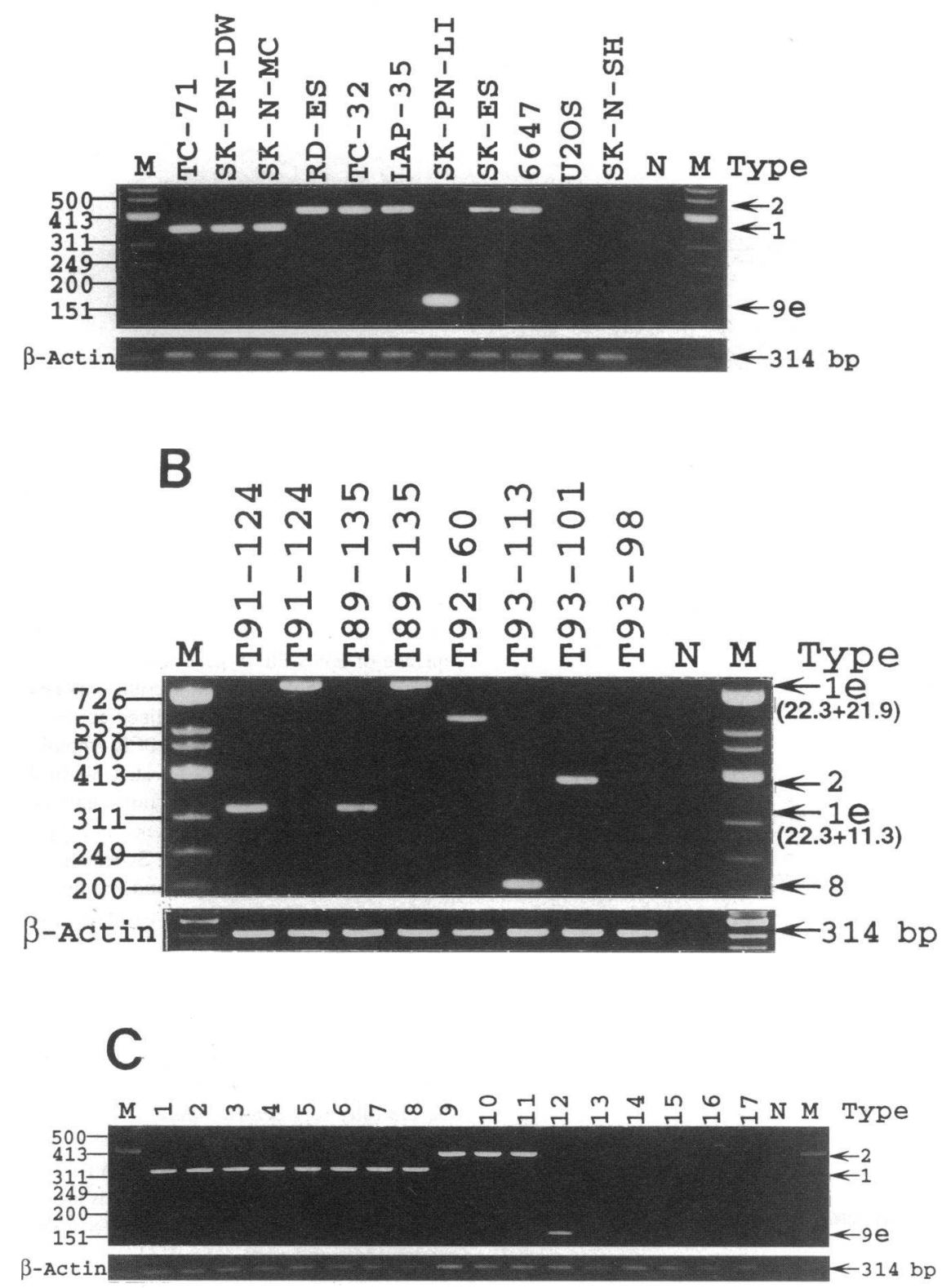

Figure 1. RT-PCR analysis of EWS-Flil and EWS-erg chimeric transcript expression in SRCT. (A) Cell lines. PCR analysis was performed on oligo-dT reverse-transcribed total RNA samples $(1 \mu \mathrm{g})$ with primers 22.1 (EWS exon 7) and 11.3 (Fli1 exon 9). Amplification products were separated by electrophoresis on $2 \%$ agarose gels and visualized by ethidium bromide staining. RNAs derived from $\mathrm{t}(11 ; 22)$-negative $\mathrm{U} 2 \mathrm{OS}$ and SK$\mathrm{N}$-SH were used as negative controls. $N$, no template; $M$, molecular weight standards ( $\phi$ X 174/HinfIII). The fusion types are indicated on the right side, and their sizes with primers 22.1 and 11.3 or 21.3 are: type 1 , $355 \mathrm{bp}$; type 2, $421 \mathrm{bp}$; and type 9e, $181 \mathrm{bp}$. The 314-bp fragment shown below is amplified using b-actin primers for quality control of the RNAs. $(B)$ Cytogenetically characterized patient samples. Samples were amplified using primers 22.3 and 11.3. EWS-erg type 1 fusions isolated from patients T91-124 and T89-135 (lanes 3 and 5) were amplified using primer 21.9 that is specific for the erg gene and does not amplify EWS-Flil fusions. The sizes of the fusion types indicated on the right are: type 1e, 328 bp (primers 22.3 and 11.3) and 735 bp (primers 22.3 and 21.9); type 2, 394 bp (primers 22.3 and 11.3); type $3 \mathrm{e}, 580$ bp (primers 22.3 and 11.3); and type 8, 202 bp (primers 22.3 and 11.3). $N$, no template; $\mathrm{M}$, molecular weight standards ( $\phi$ X 174/HinfIII). (C) Cytogenetically uncharacterized samples. PCR analysis was performed on 17 cytologically, histologically, and immunohistochemically confirmed SRCTs. Included were eight ESs (lanes 15 and 10-12), three metastatic ESs (lanes 6-8), one PNET (lane 9), two small cell osteosarcomas (lanes 13 and 14), and three non-Hodgkin lymphomas of bone (lanes $15-$ 17). Samples were amplified using primers 22.3 and 11.3, and the sizes of the fusion types are indicated in $B$. $N$, no template; $\mathrm{M}$, molecular weight standards ( $\phi$ X 174/HinfIII). prepared as described previously (25). Overlapping YAC clones $\mathrm{A} 125 \mathrm{~B} 12$ and $\mathrm{B} 19 \mathrm{C} 12$ from the Washington University human genomic YAC library were shown previously to be colinear and to contain the human erg gene (29). To confirm that the YAC strains A125B12 and B19C12 contained the desired human insert, PCR analysis with two sets of primers corresponding to the $5^{\prime}$ and $3^{\prime}$ regions of the human erg gene was performed. Primers for the erg $5^{\prime}$ region were erg5S (5'-CCTCTCGGTTATTCCAGGATC-3') (forward) and erg5A (5'GTCCGGGACAGTCTGAATCAT-3') (reverse). Primers for the erg $3^{\prime}$ region were erg3S (5'-TTCAAGATGACGGATCCCGAC-3') (forward) and primer 21.9 (reverse). Fluorescent in situ suppression hybridization (FISSH) analysis using YAC clones A125B12 and B19C12 was carried out as reported (30). For two-color FISSH, YAC A125B12 DNA was labeled with biotin-11-dUTP (ENZO Diagnostics, Syosset, NY), and YAC B19C12 DNA was labeled with digoxigenin-11-dUTP (Boehringer Mannheim Corp., Indianapolis, IN) by random priming. Hybridization and posthybridization washes of the slides were carried out as described (25). After posthybridization washes, slides hybridized only to biotin-labeled probes were incubated in avidin-fluorescein as described (25). Slides hybridized to both biotin- and digoxigenin-labeled probes were amplified and detected as described (31).

\section{Results}

Identification of distinct EWS-Flil and EWS-erg fusion isoforms in ES and PNET without $t(11 ; 22)(q 24 ; q 12)$ translocation. To define the chromosomal translocations and/or gene fusions in cases with variant rearrangements, we performed molecular analysis on a variety of cell lines and tumor material. RD-ES and SK-PN-LI cell lines (Table I) were analyzed by RT-PCR. The PCR amplification product generated using reverse-transcribed RNA from cell line RD-ES as a template and primers 


\section{EWS-Fli1 Type 8}

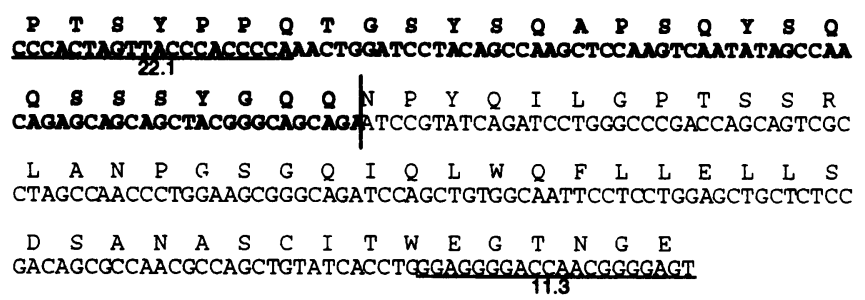

EWS-erg
Type $1 e$
$\& 9 e$

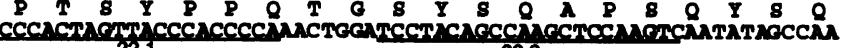

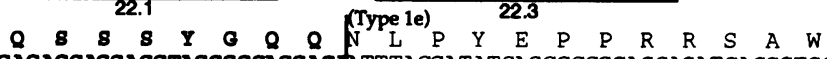

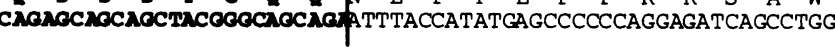
$\begin{array}{cccccccccccccccccccc}\text { T } & \text { G } & \text { H } & \text { G } & \text { H } & \text { P } & \text { T } & \text { P } & \text { Q } & \text { S } & \text { K } & \text { A } & \text { A } & \text { Q } & \text { P } & \text { S } & \text { P } & \text { S } & \text { T } & \text { V } \\ \text { ACCGGTCACGGCCACCCCACGGCCCAGTCGAAAGCTGCTCAACCATCTCCTTCCACAGTG }\end{array}$ $\begin{array}{llllllllllllllllllll}P & K & T & E & D & Q & R & P & Q & L & D & P & Y & Q & I & L & G & P & T & S\end{array}$ CCCAAAACTGAAGACCAGCGTCCTCAGTTAGATCCTTATCAGATTCTTGGACCAACAAGT $S \quad R \quad L \quad A \quad N \quad P \quad G$ (Type 9e)

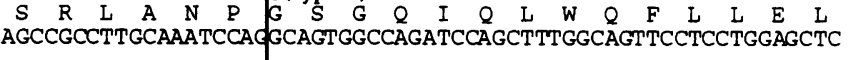

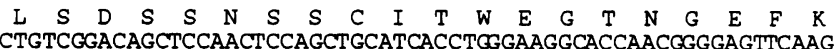
$\begin{array}{llllllllllllllllllllllll}M & T & D & P & D & E & V & A & R & R & W & G & E & R & K & S & K & P & N & M\end{array}$ ATGACGGATCCCGACGAGGTGGCCCGGCGCTGGGGAGAGCGGAAGAGCAAACCCAACATG $\begin{array}{llllllllllllllllllll}N & Y & D & K & L & S & R & A & L & R & Y & Y & Y & D & K & N & I & M & T & K\end{array}$ AACTACGATAAGCTCAGCCGCGCCCTCCGTTACTACTATGACAAGAACATCATGACCAAG

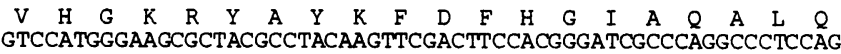

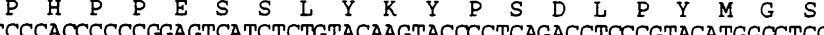
$\begin{array}{llllllllllllllllllll}\text { Y } & H & A & H & P & Q & K & M & N & F & V & A & P & H & P & P & A & L & P & V\end{array}$ TATCACGCCCACCCACAGAAGATGAACTTTGTGGCGCCCCACCCTCCAGCCCTCCCCGTG $\begin{array}{cccccccccccccccccccc}\text { T } & S & S & S & F & F & \text { A } & \text { A } & \text { P } & \text { N } & \text { P } & \text { Y } & \text { W } & \text { N } & \text { S } & \text { P } & \text { T } & \text { G } & \text { G I } & \text { I } \\ \text { ACATCTTCCAGTTTTTTTGCTGCCCCAAACCCATACTTGAATTCACCAACTGGGGGTATA }\end{array}$ $\begin{array}{llllllllllllll}\text { Y } & \text { P } & \text { N } & \text { T } & \text { R } & \text { L } & \text { P } & \text { T } & \text { S } & \text { H } & \text { M } & \text { P } & \text { S } & \text { H }\end{array}$ TACCCCAACACTAGGCTCCOCACCAGCCATATGCCTTCTCAT
\end{abstract}

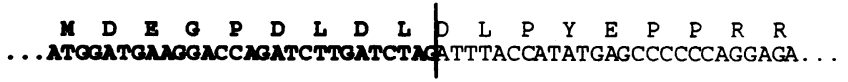

Figure 2. Molecular analysis of EWS-erg and EWS-Flil chimeric mRNAs. $(A)$ Nucleotide sequence and predicted amino acid sequence of EWS-Fli1 type 8 and EWS-erg type $1 \mathrm{e}, 3 \mathrm{e}$, and $9 \mathrm{e}$ fusion transcripts obtained by RT-PCR. Sequences underlined correspond to the primers used for PCR amplification and their names are indicated. Vertica bars indicate the different junctions, and the contribution of the EWS sequence is highlighted in bold characters. $(B)$ Schematic representation of EWS, Fli1, and erg functional domains and their locations on the nonrearranged proteins and the fusion proteins translated from the cDNAs represented in $(A)$. The RNA-binding domain of EWS ( $R N A B D$ ) is replaced by the ETS domains (ETS D) of Flil or erg, depending on the fusion type. Fusion proteins type 8 and type $9 \mathrm{e}$ are fully represented, while type 1e and type $3 \mathrm{e}$ can be deduced from type $9 \mathrm{e}$ by the insertion of 59 additional $\mathrm{erg}$ amino acids. In type $3 e, 84$ additional amino acids are derived from the EWS sequence. Interrupted codons are indicated. Type $3 e$

22.1 and 11.3 was $421 \mathrm{bp}$ in size (Fig. $1 A$ ). Nucleotide sequence analysis of the hybrid transcript revealed in-frame junctions between EWS codon 265 and Flil codon 197, which is identical to type 2 fusion described previously (6). Amplification of SK-PN-LI cDNAs resulted in a product of $181 \mathrm{bp}$ derived from the fusion of EWS with the human erg gene, located on chromosome 21 (Fig. $1 \mathrm{~A}$ ). Although not reported previously (24), a $t(21 ; 22)(q 22 ; q 12)$ translocation was observed in karyotypes prepared from the SK-PN-LI cell line. Basic local alignment search tool (32) analysis (BLAST) of the GenBank database with primer 11.3 nucleotide sequence revealed $90 \%$ homology with the region extending from nucleotide 842 to 861 of the published erg sequence (28). Therefore, primer 11.3 can amplify both EWS-Fli1 and EWS-erg fusion transcripts. Nucleotide sequence analysis of the fragment revealed an inframe fusion occurring between the first base (A) of codon 265 of EWS (Ser) and the $\mathrm{G}$ in the second position of codon 192 of $\operatorname{erg}$ (Gly), creating a new AGC codon for a serine residue (Fig. 2, $A$ and $B$ ). This region of the erg gene shows $98 \%$ homology with the exon 9 region of Flil, and we will therefore refer to this fusion as type 9e. Six different erg isoforms have been described, generated by alternative splicing events $(28$, $33,34)$. The erg moieties cloned in this study are in a region common to all the described erg isoforms. The erg-1 cDNA sequence was therefore used for nucleotide and codon numeration (GenBank database accession number M21535). OligodT-primed cDNAs from five SRCT patients that cytogenetically do not contain the typical $\mathrm{t}(11 ; 22)(\mathrm{q} 24 ; \mathrm{q} 12)$ translocation (Table $I$ ) were amplified using the combination of primers 22.3 and 11.3 (Fig. $1 \mathrm{~B}$ ). Tumors from patients T91-124 and T89-135 showed a 328-bp amplification product consistent with an EWS-Fli1 type 1 fusion. Surprisingly, however, sequence 
F1i1
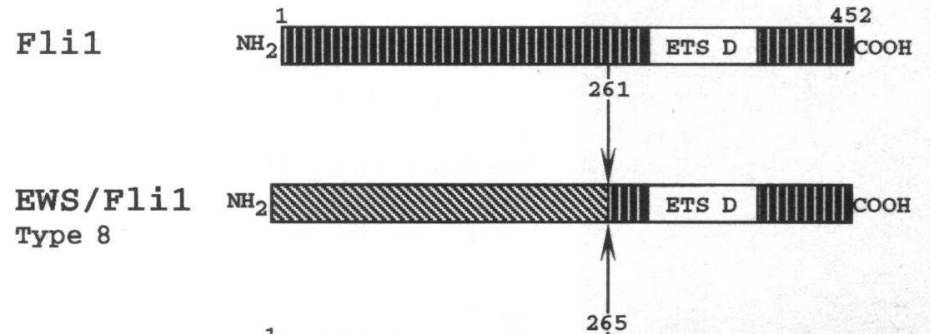

EWS

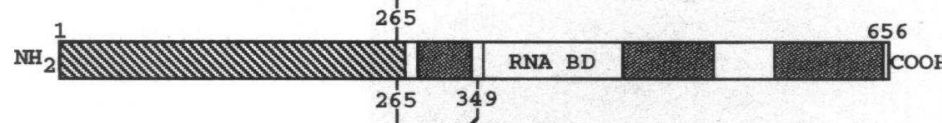

EWS/erg

Type $9 e$

erg

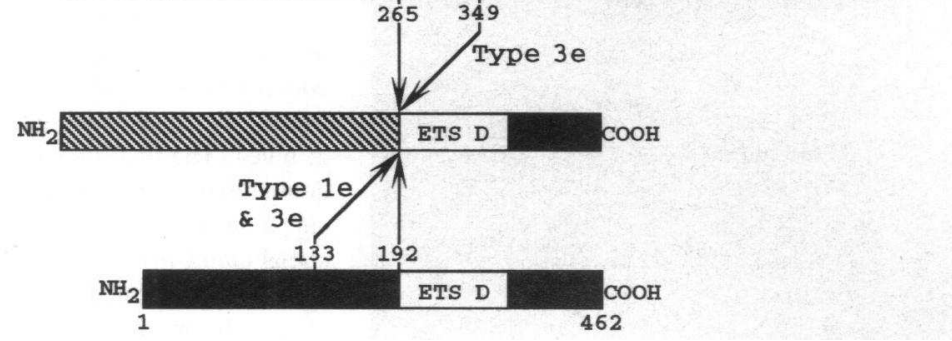

Figure 2. Continued

analysis revealed a novel in-frame EWS-erg fusion occurring between the first base (A) of codon 265 of EWS (Ser) and the $A$ in the second position of codon 133 of erg (Asp), creating a new AAT codon for an asparagine residue (Fig. 2, $A$ and $B$ ). Because of this similarity in size with EWS-Fli1 fusion type 1, we define this fusion as type 1e. To improve the quality and specificity of the PCR amplification of EWS-erg fusions, a new reverse primer, 21.9, was designed. Primer 21.9 is in the region immediately downstream of the erg ETS domain (nucleotides 1249-1268 of GenBank M21535) that does not show homology with Fli1. As expected, amplification of T91-124 and T89-135 cDNAs using primers 22.3 and 21.9 resulted in single amplification products of $735 \mathrm{bp}$ (Fig. $1 \mathrm{~B}$, lanes 3 and 5). The same combination of primers failed to detect the EWS-Fli1 transcripts present in SK-PN-DW and RD-ES cell lines (data not shown), confirming the predicted specificity of primer 21.9 for the human erg gene. Reexamination of karyotypes from case T91-124 demonstrated a translocation involving 21q22 and a possible translocation involving 22q12. Case T89-135 was missing one chromosome 22 , and no obvious rearrangements of chromosome 21 were seen. To confirm that the rearranged erg in fact resulted in disruption of the gene on chromosome 21 , we performed interphase FISSH analysis with two overlapping YAC clones encompassing the erg gene (29). PCR analysis demonstrated that YAC clone A125B12 contains the 3' region of erg and not the $5^{\prime}$ and, conversely, YAC B19C12 contains the $5^{\prime}$ and not the $3^{\prime}$ region (data not shown, see Methods for details on primer sequences). Together these YACs span $\sim 430 \mathrm{~kb}$ of genomic DNA on human chromosome 21q22.2 (29). After FISSH, $46 \%$ of the nuclei from tumor sample T89-135 contained three hybridization signals (Fig. 3), one yellow signal due to the overlap of the two YACs on the normal chromosome 21 , one green signal corresponding to YAC B19C12 (5' erg region), and one red signal corresponding to the translocated $3^{\prime}$ erg region contained in YAC A125B12. The remaining nuclei displayed two yellow hybridization signals indicating two normal erg genes and probably represent normal diploid stromal cells infiltrating the tumor biopsy. A third, distinct type of EWSerg fusion was found in tumor T92-60. This tumor demonstrated what appeared to be the derivative 22 from a $t(11 ; 22)(q 24 ; q 12)$ translocation. A single fragment of $580 \mathrm{bp}$ was detected after 30 cycles of amplification with primers 22.3 and 11.3 (Fig. $1 \mathrm{~B}$ ). Sequence analysis of the region encompassing the fusion breakpoint revealed an in-frame junction between the first base ( $\mathrm{G}$ ) of codon 349 of EWS (Gly) and the $A$ in the second position of codon 133 of erg (Asp), creating a new GAT codon for an asparagine residue (Fig. 2, $A$ and $B$ ). EWS codon 349 was reported to be interrupted by fusion with Fli1 codon 219. This was classified as type $3(6)$. Because of the striking similarities of the two fusion mechanisms, we refer to this new EWS-erg fusion as type 3e. An EWS-Flil fusion isoform was isolated in tumor T93-113. Cytogenetic studies from this tumor demonstrated a variant $\mathrm{t}(12 ; 22 ; 22)$ translocation in the presence of two apparently normal chromosomes 11 . A representative karyotype is shown in Fig. 4. One $\operatorname{der}(22)$ is similar to the $\operatorname{der}(22)$ seen as a result of the typical $t(11 ; 22)(q 24 ; q 12)$ translocation. RT-PCR amplification with primers 22.3 and 11.3 (Fig. $1 B$ ) produced a 202-bp fragment resulting from an in-frame junction between the $A$ in position one of EWS codon 265 (Ser) and the A in position 2 of Flil codon 261 (D), the first codon of Fli1 exon 8 (Fig. 2, $A$ and $B$ ). A cryptic translocation involving chromosomes 11 and 22 was thus present in this tumor. We termed this EWS-Flil fusion as type 8 . Despite amplification of the $\beta$-actin gene (Fig. 1 $B$ ), tumor T93-98 did not demonstrate EWS-Fli1 or EWS-erg fusions by RT-PCR analysis. The diagnosis for this patient was undifferentiated sarcoma consistent with alveolar rhabdomyosarcoma. Cytogenetic studies demonstrated translocations involving both chromosomes 22 , although neither resembled the $\operatorname{der}(22)$ of a $t(11 ; 22)(\mathrm{q} 24 ; \mathrm{q} 12)$ translocation. The presumed 22q11-12 breakpoints are proximal to EWS and suggest the presence of another gene on chromosome 22 involved in the development of solid tumors.

Incidence of the various fusion transcripts in ES/PNET 


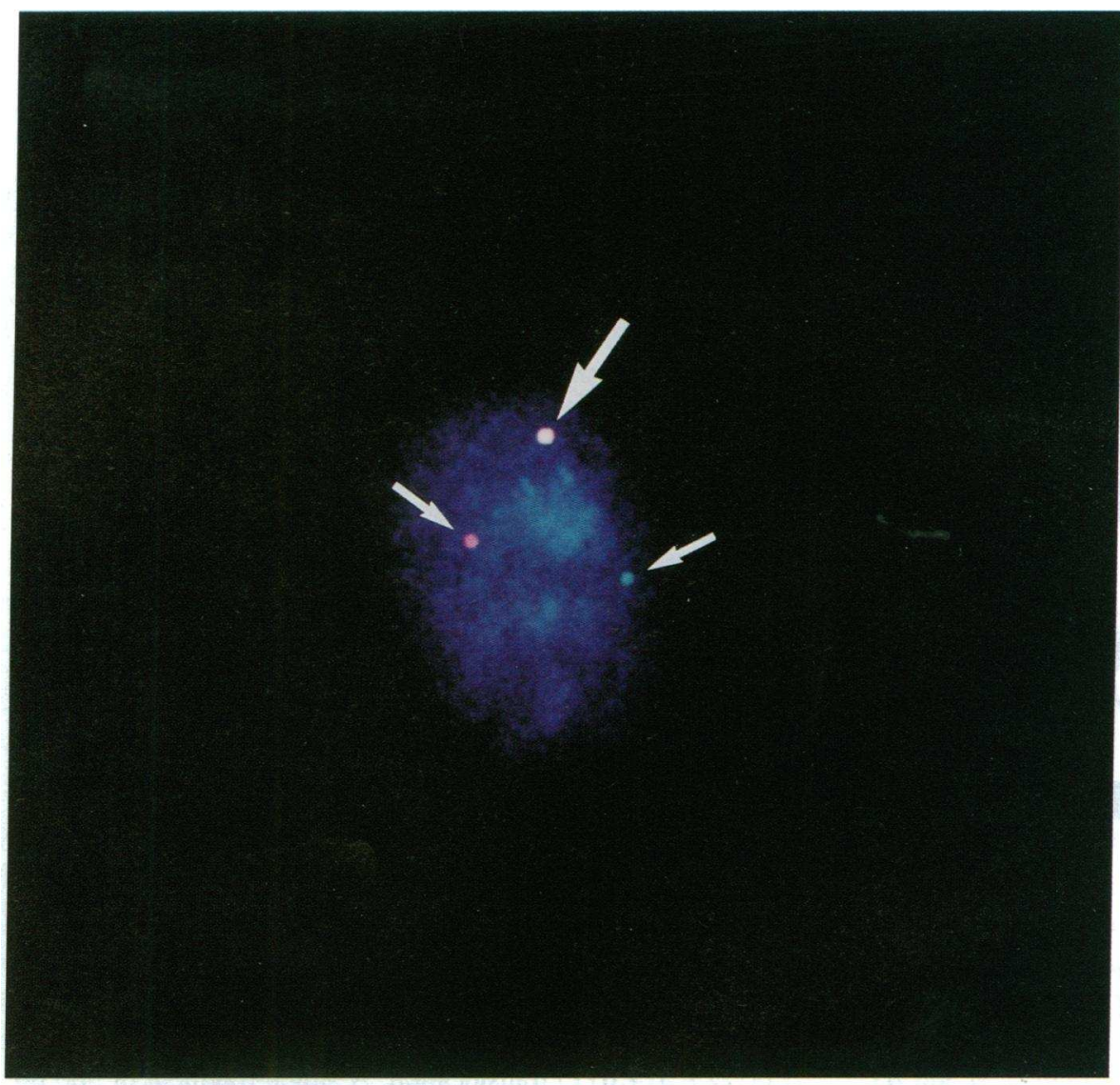

Figure 3. FISSH with erg YAC clones. Interphase nucleus from ES tumor T89-135 after two-color FISSH with YACs A125B 12 and $\mathrm{B} 19 \mathrm{C} 12$, biotin- and digoxigenin-labeled, respectively. Hybridization signals were detected using Texas red avidin and fluorescein-anti-digoxigenin. Data were collected, and images were reconstructed using a confocal microscope (MRC-600; Bio-Rad, Cambridge, MA). Separate images of each fluorochrome were collected and digitally superimposed (image one: red and green). Delineation of the nucleus was obtained by blue pseudocoloring of a third image collected with the $610-\mathrm{nm}$ filter to visualize the nucleus stained by diluted propidium iodide (image 2: blue). The final image was obtained by double-exposure photography of images 1 and 2 on the computer screen. The yellow signal (thick arrow) corresponds to the normal, nontranslocated erg allele and is generated by the proximity of green/red hybridization signals of the two overlapping YAC clones. Disruption of the erg gene with the translocation is visualized by separation of the red (left) and green (right) signals (thin arrows) corresponding to YAC A125B 12 (erg 3' region: ETS domain) and $\mathrm{B} 19 \mathrm{C} 12$ (erg 5' region), respectively.

carrying the typical $t(11 ; 22)$ translocation and in cytogenetically uncharacterized tumors. To study the incidence of the different fusion transcripts and their occurrence in tumors with different phenotypes and cytogenetic abnormalities, we extended our RT-PCR analysis to 6 cell lines and 1 patient sample (T93-101) with typical $\mathrm{t}(11 ; 22)(\mathrm{q} 24 ; \mathrm{q} 12)$ translocations, 1 cell line with a complex $t(2 ; 11 ; 22 ; 21)$ translocation, and 17 tumor samples with cytologically, histologically, and immunohistochemically confirmed SRCT for which cytogenetic data were not available. An EWS-Fli1 type 1 chimeric transcript was found in eight unkaryotyped Ewing's tumors (Fig. $1 C$ ) and in three cell lines (Fig. $1 A$ ). Of the cell lines, one was derived from ES (TC-71), one from a PNET (SK-PN-DW), and one from an AT (SK-N-MC) carrying a complex $t(2 ; 11 ; 22 ; 21)$

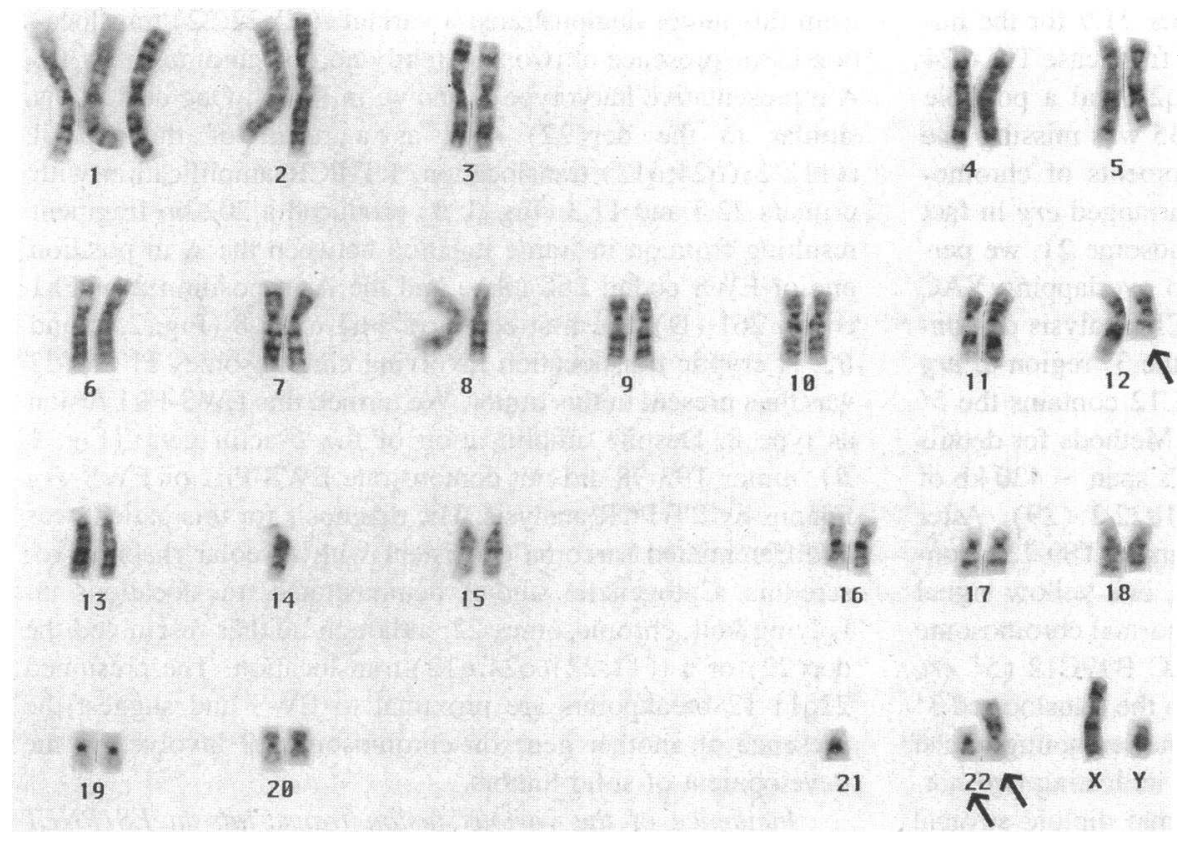

Figure 4. Representative karyotype from case T93-113. Arrows point to the der(12) and the two derivative chromosomes 22 . The chromosome 22 on the left is similar to the $\operatorname{der}(22)$ seen in a typical $t(11 ; 22)(\mathrm{q} 24 ; \mathrm{q} 12)$ translocation. The $\operatorname{der}(22)$ on the right contains the long arm of chromosome 12 (q14 $\rightarrow$ qter) translocated to 22p. The $\operatorname{der}(12)$ contains the long arm of chromosome 22 (q12 $\rightarrow$ qter $)$. The chromosomes 11 appear to be normal. Loss of a chromosome 14 and 21 are random, and there is also an $i(1 q)$. 
translocation. Karyotypes prepared from the SK-PN-DW cell line demonstrated a typical $\mathrm{t}(11 ; 22)(\mathrm{q} 24 ; \mathrm{q} 12)$ translocation, as well as the monosomy 11 which had been reported previously (24). An EWS-Fli1 Type 2 transcript was found in 3 of the 17 tumors (Fig. $1 C$ ): 2 Ewing's Sarcomas and 1 PNET of the bone, in 4 cell lines (Fig. $1 \mathrm{~A}$ ): 1 was derived from a PN (TC32), 1 from a PNET of bone (LAP-35), 2 from ES (SK-ES; 6647), and in ES patient T93-101 (Fig. $1 \mathrm{~B}$ ). 1 additional ES among the 17 SRCT demonstrated a type 9e EWS-erg fusion (Fig. 1 C). Our RT-PCR assay did not reveal the presence of the type 4 fusion in PN cell line TC-32, which had been described previously (14). Despite amplification of the $\beta$-actin gene (Fig. 1 $C$ ). RNA from five unkaryotyped tumor samples did not result in amplification of fusion transcripts. On the basis of cytologic, histologic, and immunohistochemical analyses, three tumors had been diagnosed as non-Hodgkin's lymphoma of bone and two as small cell osteogenic sarcoma.

\section{Discussion}

Molecular studies of primary tumor specimens from ES and PNET patients as well as established cell lines demonstrate that the majority of tumors contain a typical $\mathrm{t}(11 ; 22)(\mathrm{q} 24 ; \mathrm{q} 12)$ translocation, resulting in a type 1 or type 2 EWS-Fli1 fusion transcript $(6,17)$. At present, there does not appear to be any correlation with tumor phenotype, and the relationship of the molecular findings to clinical patient outcome is unknown. In this report, we describe five tumor specimens which were selected for study based on the cytogenetic finding of a rearranged or missing chromosome 22 , in the presence of normal chromosomes 11 . In one case with a variant $\mathrm{t}(12 ; 22 ; 22)(\mathrm{q} 14 ; \mathrm{p} 1 ; \mathrm{q} 12)$ translocation, we identified a novel EWS-Fli1 fusion (type 8). This tumor therefore had a cryptic or masked translocation involving chromosomes 11 and 22 and is similar to what has been seen in chronic myeloid leukemia (35). Three of these tumors, as well as one cell line, and an additional SRCT in which cytogenetic analysis was not performed do not have an EWSFli1 fusion, but contain one of three EWS-erg fusion transcripts. In each case, the $\mathrm{NH}_{2}$-terminal domain of EWS is fused to the ETS DNA-binding domain of the erg gene. ERG is a member of the ETS family of genes which share highest homology with Fli1 $(11,12)$ and was found to be rearranged in human myeloid leukemia with $\mathrm{t}(16 ; 21)$ translocation (36).

In recent studies (Zucman, J., T. Melot, B. Plougastel, L. Selleri, M. Giovannini, G. A. Evans, O. Delattre, and G. Thomas, manuscript submitted for publication), we determined the genomic organization and exon structure of the Flil gene and showed that it spans $120 \mathrm{~kb}$ of genomic DNA and is encoded by nine exons. Flil exon 9 encodes the ETS domain and begins with a conserved glycine codon that is split by the 8th intron/9th exon junction between nucleotides in position one and two (G/GA). Although the genomic structure and exon organization of the human erg gene have not been determined yet, the striking amino acid sequence identities and the high degree of conservation of intron/exon boundaries found for the other members of ETS family for which the genomic structure is known (Fli1, ETS1 and ETS2) imply that erg has an exon structure similar to that of Fli1. Furthermore, analysis of the EWS-erg fusions we have isolated indicates two potential exon/ intron boundaries. Flil codon 219 (asparagine), which is split in EWS-Fli1 type 1 and 3 fusions (6), is interrupted by an intron/exon junction. In the EWS-erg fusion types $1 \mathrm{e}$ and $3 \mathrm{e}$, we found erg codon 133 (asparagine) to be split between the G in the first position and the $\mathrm{A}$ in the second position, indicating a potential intron/exon junction. Another intron/exon junction could interrupt codon 192 of erg (glycine) between the $G$ in the first position and the $G$ in the second position which was found to be fused to EWS in EWS-erg fusion type 9e. This fusion isoform, connecting the $\mathrm{NH}_{2}$-terminal domain of EWS directly to the erg ETS domain, has not been described for Fli1 and may indicate that the ETS domain itself is sufficient to induce transformation. In fact, similar studies (37-39) have demonstrated that the EWS/Flil chimeric protein is a transcriptional activator, suggesting that it deregulates the target genes of Fli1.

The mapping of marker D21S60 to the erg YAC A125B12 (29) gives us additional information regarding the genomic organization of erg. In an integration map of human chromosome 21, D21S60 is located centromeric to the erg gene (40). In addition to our PCR results, this evidence strongly suggests that the erg gene is transcribed in a telomere to centromere direction. Since a simple balanced translocation would juxtapose the 5' region of EWS to the 5' end of erg and not the 3' end, this putative erg orientation suggests that a productive EWS-erg fusion requires a complex chromosomal rearrangement. Additional FISSH studies with chromosome-specific painting probes and probes encompassing or flanking the translocation breakpoints will be necessary to precisely define the dynamics of these chromosomal rearrangements.

Another rationale for this study was to analyze the incidence of the different fusion types in a spectrum of tumors with known phenotype. The breakpoints resulting in EWS/Fli1 type 1 and type 2 fusions appear to be, by far, the most common, and the occurrence of either type 1 or 2 does not seem to be correlated to whether the tumors are considered to be ESs or PNETs. Although we have analyzed a significant number of tumors, analysis of a larger series is necessary to determine whether the occurrence of distinct fusion types is a random event. Considering the number of novel fusion transcripts we have identified in a relatively small number of cases, we predict that additional studies will probably reveal other fusion isoforms occurring between EWS-Fli1, EWS-erg, and fusion of EWS with genes on other chromosomes. Further biological studies are needed to determine the role of the fusion transcripts in the development of these tumors. At present, RT-PCR and FISSH clearly provide a sensitive means by which to identify the molecular events involved in the standard, variant, and masked translocations in ES and PNET.

Note added in proof. Since submission of this article two independent groups (Zucman, J., T. Melot, C. Desmaze, J. Ghysdael, B. Plougastel, M. Peter, J. M. Zucker, T. J. Triche, D. Sheer, C. Turc-Carel, et al. 1993. EMBO [Eur. Mol. Biol. Organ.] J. 12:4481-4487) (Sorensen, P. H. B., S.-L. Lessnick, D. Lopez-Terrada, X. F. Liu, T. J. Triche, and C. T. Denny. 1994. Nat. Genet. 6:146-151) have reported similar EWSerg fusion transcripts.

\section{Acknowledgments}

We are indebted to Dr. O. Delattre and Dr. G. Thomas, Laboratory of Tumor Genetics, Institut Curie (Paris, France), for invaluable discussion and for making their unpublished results available. We thank Dr. T. Triche, Children's Hospital of Los Angeles (Los Angeles, CA) for the generous gift of cell lines TC-71, TC-32, and 6647; and Dr. L. Helson and Dr. C. Helsen, New York Medical College (Valhalla, NY) for cell lines SK-PN-DW and SK-PN-LI. We wish to thank Dr. P. Close, Hershey Medical Center; Dr. J. Porter, Albany Medical Center; Dr. D. 
Baker, Princess Margaret Hospital, Perth, Western Australia; Dr. C. Rubin, The University of Chicago Medical Center; and Dr. K. Leung, Kaiser Permanente, for contribution of patient samples.

M. Giovannini was a recipient of an Italian Research Council (CNR) fellowship. This work was supported by grant HG00202 from the Department of Energy, grants from the G. Harold and Leyla Y. Mathers Foundation (G. A. Evans), and grants CA 47983 (J. A. Biegel) and CA39926 (B. S. Emanuel) from the National Cancer Institute.

\section{References}

1. Huvos, A. G. 1991. Ewing's sarcoma. In Bone Tumors. J. Mitchell, editor. W. B. Saunders Co., Philadelphia. 523-552.

2. Aurias, A., C. Rimbaut, D. Buffe, J. Dubousset, and A. Mazabraud. 1983. Chromosomal translocation in Ewing's sarcoma. N. Engl. J. Med. 309:496-497.

3. Turc-Carel, C., I. Philip, M. P. Berger, T. Philip, and G. M. Lenoir. 1983 Chromosomal translocation in Ewing's sarcoma. N. Engl. J. Med. 309:497-498.

4. Turc-Carel, C., A. Aurias, F. Mugneret, S. Lizard, I. Sidaner, C. Volk, J. P. Thiery, S. Olschwang, I. Philip, M. P. Berger, et al. 1988. Chromosome study of Ewing's sarcoma (ES) cell lines. Consistency of a reciprocal translocation $\mathrm{t}(11 ; 22)(\mathrm{q} 24 ; \mathrm{q} 12)$. Cancer Genet. Cytogenet. 32:229-238.

5. Whang-Peng, J., T. J. Triche, T. Knutsen, J. Miser, S. Kao-Shan, S. Tsai, and M. A. Israel. 1986. Cytogenetic characterization of selected small round cell tumors of childhood. Cancer Genet. Cytogenet. 21:185-208.

6. Delattre, O., J. Zucman, B. Plougastel, C. Desmaze, T. Melot, M. Peter, H. Kovar, I. Joubert, P. de Jong, G. Rouleau, et al. 1992. Gene fusion with an ETS DNA-binding domain caused by chromosome translocation in human tumours. Nature (Lond.). 359:162-165.

7. Zucman, J., O. Delattre, C. Desmaze, A. L. Epstein, G. Stenman, F. Speleman, C. D. M. Fletchers, A. Aurias, and G. Thomas. 1993. EWS and ATF-1 gene fusion induced by $\mathrm{t}(12 ; 22)$ translocation in malignant melanoma of soft parts. Nature Genet. 4:341-345.

8. Crozat, A., P. Aman, N. Mandahl, and D. Ron. 1993. Fusion of CHOP to a novel RNA-binding protein in human myxoid liposarcoma. Nature (Lond.) 363:640-644.

9. Barr, F. G., N. Galili, J. Holick, J. A. Biegel, G. Rovera, and B. S. Emanuel. 1993. Rearrangement of the PAX3 paired box gene in the paediatric solid tumor alveolar rhabdomyosarcoma. Nature Genet. 3:113-117.

10. Galili, N., R. J. Davis, W. J. Fredericks, S. Mukhopadhyay, F. J. Rauscher III, B. S. Emanuel, G. Rovera, and F. G. Barr. 1993. Fusion of a fork head domain gene to PAX3 in the solid tumour alveolar rhabdomyosarcoma. Nature Genet. 5:113-117.

11. Prasad, D. D. K., V. N. Rao, and S. P. Reddy. 1992. Structure and expression of human Fli-1 gene. Cancer Res. 52:5833-5837.

12. Wasylyk, B., S. L. Hahn, and A. Giovane. 1993. The ets family of transcription factors. Eur. J. Biochem. 211:7-18.

13. Kenan, D. J., C. C. Query, and J. D. Keene. 1991. RNA recognition: towards identifying determinants of specificity. Trends Biochem. Sci. 16:214220.

14. May, W. A., M. L. Gishizki, S. L. Lessnick, L. B. Lunsford, B. C. Lewis, O. Delattre, J. Zucman, G. Thomas, and C. T. Denny. 1993. Ewing sarcoma 11;22 translocation produces a chimeric transcription factor that requires the DNAbinding domain encoded by FLI1 for transformation. Proc. Natl. Acad. Sci. USA. 90:5752-5756.

15. Turc-Carel, C., P. Dal Cin, U. Rao, C. Karakousis, and A. Sandberg. 1988 Recurrent breakpoint at $9 \mathrm{q} 31$ and $22 \mathrm{q} 12.2$ in extraskeletal myxoid chondrosarcoma. Cancer Genet. Cytogenet. 30:145-150.

16. Bonin, G., C. Scamps, C. Turc-Carel, and M. Lipinski. 1993. Chimeric EWS-FLI1 transcript in a Ewing Cell line with a complex $t(11 ; 22 ; 14)$ translocation. Cancer Res. 53:3655-3657.

17. Zucman, J., O. Delattre, C. Desmaze, B. Plougastel, I. Joubert, T. Melot, M. Peter, P. De Jong, G. Rouleau, A. Aurias, and G. Thomas. 1992. Cloning and characterization of the Ewing's sarcoma and peripheral neuroepithelioma t $(11 ; 22)$ translocation breakpoints. Genes Chromosomes \& Cancer. 90:271-277.

18. Morris, C. M., N. Heisterkamp, M. A. Kennedy, P. H. Fitzgerald, and J. Groffen. 1990. Ph-negative chronic myeloid leukemia: molecular analysis of ABL insertion into M-BCR on chromosome 22. Blood. 76:1812-1818.
19. Gu, Y., T. Nakamura, H. Alder, R. Prasad, O. Canaani, G. Cimino, C. M. Croce, and E. Canaani. 1992. The $\mathrm{t}(4 ; 11)$ chromosome translocation of human acute leukemias fuses the ALL-1 gene, related to Drosophila trithorax, to the AF-4 gene. Cell. 71:701-708

20. Tkachuk, D. C., S. Kohler, and M. L. Cleary. 1992. Involvement of a homolog of Drosophila trithorax by $11 \mathrm{q} 23$ chromosomal translocations in acute leukemias. Cell. 71:691-700.

21. Djabali, M., L. Selleri, P. Parry, M. Bower, B. D. Young, and G. A. Evans. 1992. A trithorax-like gene is interrupted by chromosome 11q23 translocations in acute leukemias. Nature Genet. 2:113-118.

22. Nakamura, T., H. Alder, Y. Gu, R. Prasad, O. Canaani, N. Kamada, R. P. Gale, B. Lange, W. M. Crist, P. C. Nowell, et al. 1993. Genes on chromosomes 4,9 , and 19 involved in 11q23 abnormalities in acute leukemia share sequence homology and/or common motifs. Proc. Natl. Acad. Sci. USA. 90:4631-4635.

23. Bagnara, G. P., M. Serra, M. Giovannini, M. Badiali, M. Stella, A. Montaldi, D. Granchi, P. Paolucci, P. Rocchi, A. Pession, et al. 1990. Establishment and characterization of a primitive neuroectodermal tumor of bone continuous cell line (LAP-35). Int. J. Cell Cloning. 8:409-424.

24. Potluri, V. R., F. Gilbert, C. Helsen, and L. Helson. 1987. Primitive neuroectodermal tumor cell lines: chromosomal analysis of five cases. Cancer Genet. Cytogenet. 24:75-86.

25. Giovannini, M., L. Selleri, J. A. Biegel, K. Scotlandi, B. S. Emanuel, and G. A Evans. 1992. Interphase cytogenetics for the detection of the $\mathrm{t}(11 ; 22)(\mathrm{q} 24 ; \mathrm{q} 12)$ in small round cell tumors. J. Clin. Invest. 90:1911-1918.

26. Biegel, J. A., R. B. Warrer, and B. S. Emanuel. 1989. Complex karyotypes in a series of osteosarcomas. Cancer Genet. Cytogenet. 38:89-100.

27. Chomczynski, P., and N. Sacchi. 1987. Single-step method of RNA isolation by acid guanidinium thiocyanate-phenol-chloroform extraction. Anal. Biochem. 162:156-159.

28. Rao, V. N., T. S. Papas, and S. P. Reddy. 1987. erg a human ets-related gene on chromosome 21: alternative splicing, polyadenylation, and translation. Science (Wash. DC). 237:635-639.

29. Tassone, F., S. Cheng, and K. Gardiner. 1992. Analysis of chromosome 21 yeast artificial chromosome (YAC) clones. Am. J. Hum. Genet. 51:12511264.

30. Selleri, L., G. G. Hermanson, J. H. Eubanks, and G. A. Evans. 1991 Chromosomal in situ hybridization using yeast artificial chromosomes. GATA (Genet. Anal. Tech. Appl.). 8:59-66.

31. Ruttledge, M. H., Y. G. Xie, F. Y. Han, M. Giovannini, M. Janson, I. Fransson, B. Werelius, O. Delattre, G. Thomas, G. Evans, and J. P. Dumanski. 1994. Physical mapping of the NF2/meningioma region on human chromosome 22q12. Genomics. 19:52-59.

32. Altschul, S. F., W. Gish, W. Miller, E. W. Myers, and D. J. Lipman 1990. Basic local alignment search tool. J. Mol. Biol. 215:403-410.

33. Duterque-Coquillaud, M., C. Niel, S. Plaza, and D. Stehelin. 1993. New human erg isoforms generated by alternative splicing are transcriptional activators. Oncogene. 8:1865-1873.

34. Rivera, R. R., M. H. Stuiver, R. Steenbergen, and C. Murre. 1993. Ets proteins: new factors that regulate immunoglobulin heavy-chain gene expression. Mol. Cell. Biol. 13:7163-7169.

35. Browett, P. J., H. M. G. Cooke, L. M. Secker-Walker, and J. D. Norton. 1989. Chromosome 22 breakpoints in variant Philadelphia translocations and Philadelphia-negative chronic myeloid leukemia. Cancer Genet. Cytogenet. 37:169-177.

36. Shimizu, K., H. Ichikawa, A. Tojo, Y. Kaneko, N. Maseki, Y. Hayashi, M. Ohira, S. Asano, and M. Ohki. 1993. An ets-related gene, ERG, is rearranged in human myeloid leukemia with $\mathrm{t}(16 ; 21)$ chromosomal translocation. Proc. Natl. Acad. Sci. USA. 90:10280-10284.

37. Ohno, T., V. N. Rao, and E. S. P. Reddy. 1993. EWS/Fli1 chimeric protein is a transcriptional activator. Cancer Res. 53:5859-5863.

38. May, W. A., S. L. Lessnick, B. S. Braun, M. Klemsz, B. C. Lewis, L. B. Lunsford, R. Hromas, and C. T. Denny. 1993. The Ewing's sarcoma EWS/Fli-1 fusion gene encodes a more potent transcriptional activator and is a more powerful transforming gene than Fli-1. Mol. Cell. Biol. 13:7393-7398.

39. Bailly, R. A., R. Bosselut, J. Zucman, F. Cormier, O. Delattre, M. Roussel, G. Thomas, and J. Ghysdael. 1994. DNA binding and transcriptional activation properties of the EWS-Flil fusion protein resulting from the $t(11 ; 22)$ translocation in Ewing sarcoma. Mol. Cell. Biol. In press.

40. Lawrence, S., A. Collins, B. J. Keats, M. Hulten, and N. E. Morton. 1993. Integration of gene maps: chromosome 21. Proc. Natl. Acad. Sci. USA. 90:72107214. 